\title{
Dispersed reinforcement in concrete technology
}

\author{
Boris Efimov ${ }^{1}$, Sergey Isachenko ${ }^{1}$, Mukhamad-Basir Kodzoev ${ }^{1, *}$, Gulzar Dosanova ${ }^{2}$ and \\ Ekaterina Bobrova $^{3}$ \\ ${ }^{1}$ NRU Moscow state university of civil engineering, 129337 Yaroslavskoye av. 26, Moscow, Russia \\ ${ }^{2}$ Karakalpak state university named after Berdakh, 230100 Academician Ch. Abdirov 1, Nukus, \\ Karakalpakstan, Uzbekistan \\ ${ }^{3}$ NRU Higher School of Economics, 101000 Myasnitskaya st. 20, Moscow, Russia
}

\begin{abstract}
The methods of disperse reinforcement of a concrete matrix with the help of fibers make it possible to manufacture structures of complex configuration and solve problems of frost resistance of products. Fiber replaces secondary reinforcement, reducing the volume of use of structural steel reinforcement. Cellular fibrous concrete is characterized by high performance properties, especially increased strength in bending and stretching, impact strength and crack resistance. As a reinforcing component, it is preferable to use mineral fibers or thin basalt fiber. The use of polyamide fiber is allowed, but there are difficulties in forming adhesive contacts between the fiber and the mineral matrix of cellular concrete. A feature of mineral fibers is that they are high adhesive to the cement matrix. One of the promising types of dispersed bulk reinforcement of lightweight concrete is the use of expanded vermiculite. Expanded vermiculite can simultaneously be considered as a reinforcing component of a lamellar structure, as a component that reduces the density of the material and its thermal conductivity, as well as improves the fire protection performance. Expanded vermiculite can be used both in piece cladding products and as a part of dry warm and fire retardant plaster mixes.*
\end{abstract}

\section{Introduction}

Despite a number of undeniable advantages, unreinforced concrete is characterized by low impact strength, low resistance to tearing, and the formation of shrinkage cracks in hardening. All this leads to a relatively low durability of articles made of such concretes [13]. These problems are solved by secondary reinforcement, which in structural concrete is carried out using steel reinforcement, and in the ceilings - metal mesh.

In recent years, technologies for the use of dispersed reinforcement of a concrete matrix have been developed with the help of polypropylene, glass, basalt and metal fibers (see Fig. 1). These methods make it possible to manufacture structures of com-plex configuration, solve problems of frost resistance of products [4-5]. Dispersed reinforcement reduces the overall weight of the structures. At a certain dosing, the fiber replaces the secondary reinforcement, reducing the use of structural steel reinforcement. Dispersion reinforcement

\footnotetext{
*Corresponding author: basir731@yandex.ru
} 
increases the plasticity of the concrete mix and reduces the formation of shrinkage cracks. Unlike the steel mesh, which "turns on" only after the concrete has cracked, the fiber prevents the appearance of cracks in the concrete at the stage when it is in a plastic state.

During the research [6-9] it was established that products reinforced with polypropylene-new fibers are characterized by considerable deformations even under small tensile loads, which is explained by low adhesion of polypropylene in the cement matrix. In addition, such products lose their strength properties over time; have high surface abrasion and flammability when exposed to open flame. The main disadvantages of metal fibers are cathodic effect and instability to aggressive environment of cement mortars. These shortcomings are devoid of concrete products reinforced with basalt fiber.

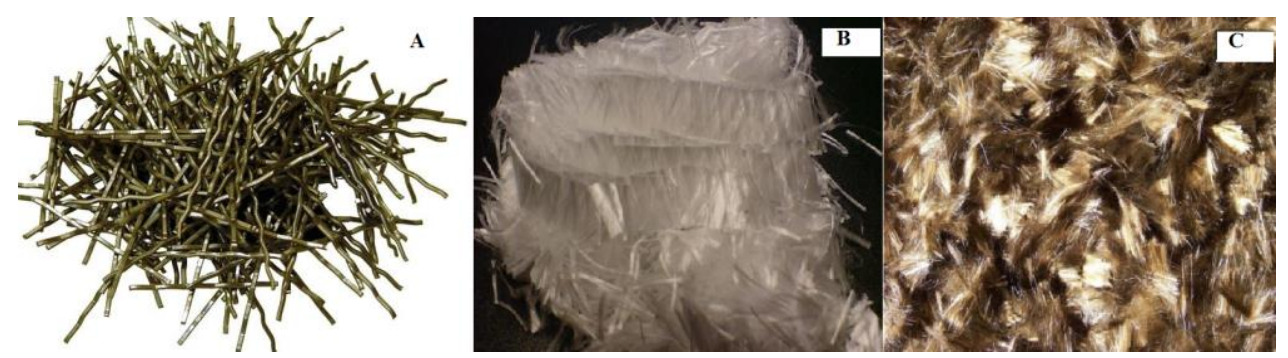

Fig. 1. Reinforcing fiber: A - steel; B - polypropylene; $\mathrm{C}$ - basalt.

The cellular concrete itself is a composite material consisting of cement and sand. Sometimes other shredded materials are used instead of sand. Reinforcement can be of two types:

- Secondary: steel reinforcement (mesh, frames, rods, wire), or spins from basalt, glass, polypropylene fibers; fiber

- Dispersed - fiber of steel, polypropylene based on glass wool, stone wool or basalt

The traditional method of reinforcement is, including for cellular concrete, the use of metal reinforcement. The reinforced products of auto-key aerated concrete include reinforced slabs and coverings, reinforced bridges, staircases and arched bridges [10]. High structural and mechanical characteristics allow reinforced products made of aerated concrete to perfectly perform the load-bearing function. At the same time, the low weight of the reinforced products makes it possible to reduce the load on the building structures.

Reinforced slabs of ceilings and coatings by the technology of the German company HEBEL from autoclaved aerated concrete began to be produced at JSC "Lipetsk Plant of Building Products" (LPBP) in 1998. In 1999 for the same technology in a village in the Republic of Belarus, cleaned at the factory building structures JSC "Zabudova", launched a similar line for the production of products from cellular concrete. Overlap plates are used for mounting of load-bearing structures of horizontal floors of any type in residential, commercial and industrial buildings [11-12].

The reinforcement of cellular concrete not with metallic materials can be carried out at 2 levels: as part of a concrete mix and by analogy with traditional reinforcement.

Composite reinforcement is usually made of polymeric or fiberglass materials in various combinations. Composite fittings have electromagnetic transparency and excellent resistance to corrosion. However, as a rule, all good has one significant drawback - a higher cost. Recently, for the reinforcement of cellular concrete, began to use fibers based on polypropylene, polyamide, and basalt and glass fiber.

By applying expanded vermiculite, it is possible to achieve a solution to this problem with a significant economic effect. Simultaneously with the decrease in the cost of maintaining heat in buildings and structures, problems such as their fire protection, sound 
reflection and sound absorption of the interior, as well as a number of other problematic issues that arise during housing improvements are solved.

Expanded vermiculite (vermiculite) is a free-flowing, porous material in the form of scaly silver or yellow particles obtained by fast firing the vermiculite concentrate hydromica containing combined water between elementary layers.

\section{Experimental}

Methods for producing fibred concrete and fiber-reinforced foamed concrete using thin polypropylene fiber, basalt fiber and expanded vermiculite were considered in the experimental procedure.

A mixture for the fiber-reinforced foamed concrete manufacture (using thin polypropylene fiber with a length of up to $12 \mathrm{~mm}$ ) was prepared in the following sequence.

Sand is first poured into the mixer (to bind the water of the previous batch), then cement is added, and everything is mixed until a uniform color mixture is obtained. Next, the mixture is closed by water in an amount corresponding to the selected reci-pe-tour. Stirring is continued until a homogeneous plastic mass is obtained. Then thin polypropylene fiber is added in an amount of $600 \mathrm{~g}$ per $1 \mathrm{~m} 3$ of the mixture. However, dosages can be either increased or decreased, depending on the specific task. Additional rectification of the fibers is not required, because the fiber in the mixture is completely dispersed.

The presence of fiber in the material provides directional crystallization of the solution, increased strength and non-shrinkage. When the cement-sand mixture is stirred, the fibrous fiber is dispersed, evenly distributed throughout the volume and produces a spatial reinforcement of the foam concrete. As a result, the structure of the foam concrete is stabilized, which prevents the formation and development of internal defects in it. 600 grams of thin polypropylene fiber contain about 300 million fibers, which do not allow the foam concrete to crack. When the foam concrete is destroyed under load, separation of the fragments is not observed - they remain connected with each other by fibers.

Then, using a foam generator, a certain portion of foam (according to the required density of foam concrete) is fed through a hose to the mixer, where it is mixed for about 120-180 s with the previously prepared cement-sand mixture. By controlling the specified density, the required strength of the foam concrete for compression is obtained. Then fiber foam concrete is fed under pressure along the sleeve into molds.

\section{Results}

With natural hardening under normal conditions (at $22^{\circ} \mathrm{C}$ ), foam concrete after 7 days accumulates $55-70 \%$ of brand strength. The yield strength of prefabricated elements is $70-$ $80 \%$ of the design grade. Installation can begin after 2-3 weeks of exposure in the air. Thermal treatment of products (in chambers or under thermo-hats) is carried out according to standard modes. To reduce the crack formation of cellular concrete, increase its strength in bending and stretching, and frost resistance, a universal technology for reinforcing it with mineral fibers (glass fibers) is proposed.

In the development of this technology, it was assumed that in a cellular concrete, the majority of the raw metal mixture, as a rule, is a siliceous component and the use of dispersed quartz-containing secondary industrial products is an extremely important task. The use of such materials can dramatically reduce energy costs for grinding the siliceous component and eliminate the consumption of natural siliceous components.

The increase in tensile strength of non-autoclaved cellular concrete is achieved by fiberreinforced matrix material with the addition of mineral wool, in particular, glass wool. The 
corrosive effect of alkaline media compositions with the addition of dolomite slag and ash, in which $\mathrm{A} 12 \mathrm{O} 3$ and $\mathrm{SiO} 2$ compounds predominate, less on glass fibers than traditional ones, in which calcium compounds predominate.

Various combinations of both acidic and basic ash solids, which were closed with alkaline components of the first group according to the classification of V.D. Glukhovsky, were used in the studies. To reduce shrinkage deformations, a certain amount of quicklime and gypsum was added to the raw mix in an amount of up to $5 \%$ of the weight of the dry components of the mixture. The tests were carried out on aerated concrete with a design density of up to $700 \mathrm{~kg} / \mathrm{m}^{3}$.

The optimal composition for the compressive strength was selected on mixtures consisting of a slag-alkali binder and ash. The ratio of lime additive to slag changed in certain parameters - at least $10 \%$ to the mass of dry components. With a constant corelation of the amount of lime to the slag, a variable amount of fly ash was introduced into the formulations and a gypsum additive was added - $5 \%$ of the mass of the dry components of the raw mix. The greatest strength was obtained by samples made on formulations with a ratio of slag-alkaline binder to ash equal to 1: 0.6. After the manufacture of the product, it was steamed at a temperature of $90-95^{\circ} \mathrm{C}$ according to the regimes recommended by the normative documents for structural and heat-insulating cellular concrete.

As with the increase in the lime-quicklime and ash content, the water absorption and shrinkage of the finished concrete is increasing, all subsequent work was carried out on the composition with $30 \%$ ash content at a constant ratio of slag to alkaline-alkaline earth activators. Dispersion of the raw mix was in the range of $3000-4000 \mathrm{~cm}^{2} / \mathrm{g}$.

To increase the tensile strength, glass wool was introduced into the raw mix. The introduction of glass wool was carried out as follows: water was poured into the running mixer, glass wool was charged and the mixture was mixed for a certain time. Then the dry components were loaded into the mixer and stirred for at least 1-2 minutes. After the introduction of the required amount of the water-aluminum slurry, stirring was continued until the blowing agent was evenly distributed in the feed mass. Investigations of the effect of glass wool additives on the strength characteristics of aerated concrete were carried out on the optimal composition with a density of $700 \mathrm{~kg} / \mathrm{m}^{3}$ in strength characteristics.

\section{Discussion}

Basalt fiber - short pieces of basalt fiber, intended for disperse reinforcement of astringent mixtures, such as concrete, in construction. The diameter of the fiber is from $20 \mu \mathrm{m}$ to 500 $\mu \mathrm{m}$. The fiber length is from $1 \mathrm{~mm}$ to $150 \mathrm{~mm}$. Basalt fiber has very good chemical resistance. Fibers with a diameter of 40 microns have a $100 \%$ resistance to water, $96 \%$ to alkali, $94 \%$ to acid. Modulus of elasticity of fiber is in the range from 7 to $60 \mathrm{GPa}$, tensile strength from 600 to $3500 \mathrm{MPa}$.

When a fiber with a diameter of $30 \mu \mathrm{m}$ is used under the influence of an aggressive medium of hardening cement, a minimum of 22 microns of working diameter of the fiber remains, which practically does not affect its strength characteristics. The use of fiber with a diameter of $12 \mu \mathrm{m}$ made of basalt roving without lubricant showed that over time it loses all strength characteristics and is sometimes completely destroyed, since the fibers, after reaction with the aggressive medium of concrete, decrease in diameter to $4 \mu \mathrm{m}$. When using fiber made from basalt roving with a lubricant, there is practically no adhesion to the cement mass. Low adhesion with a cement binder also has polyamide and propylene fibers.

Concrete products, reinforced with basalt fiber, characterized by increased durability, provide a high degree of compression, frost resistance and other. All this is explained by the fact that the structure of concrete reinforced with basalt fiber is close to the structure of reinforced cement with steel mesh reinforcement. However, basalt fiber has a higher 
strength and is resistant to deformation, because the fiber reinforcing it provides a higher degree of dispersion of reinforcement of concrete stone and the basalt material itself has a higher strength than the steel mesh strength.

Studies carried out using a JEOL JSM-6460 LV raster electron microscope at 4000-fold magnification showed that the contact area between the fiber and the matrix is characterized by tight contact of surfaces and the absence of cracks and gaps (see Fig. 2).

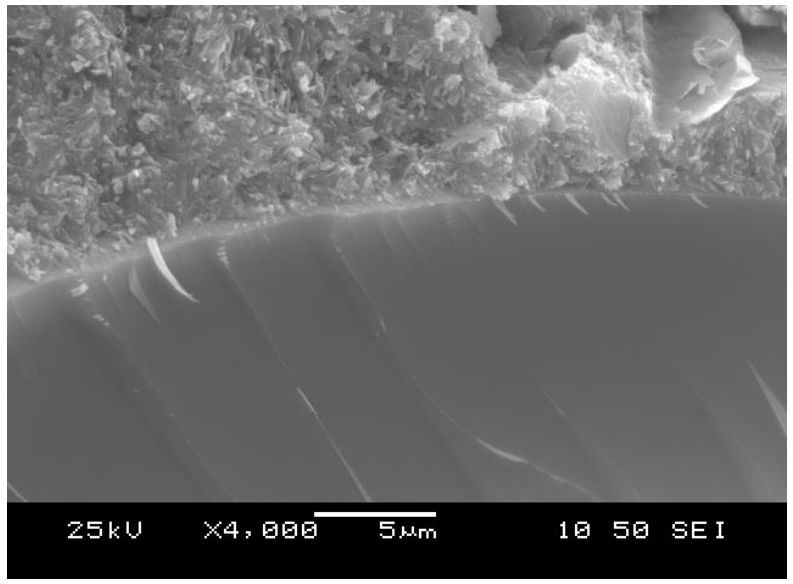

Fig. 2. The boundary between the fiber and matrix.

As you know the fiber material under the action of aggressive environment of cement reacts with the receipt of neoplasms. There is a partial destruction of the fiber, the value of which depends on time. On average, destruction occurs to a depth of $4 \mu \mathrm{m}$. The neoplasms strengthen the connection of the fiber with the cement matrix.

When using fiber with a diameter of $30 \mu \mathrm{m}$ under the influence of aggressive environment of hardening cement remains at least $22 \mu \mathrm{m}$ of the working diameter of the fiber, which practically does not affect its strength characteristics. The use of fiber with a diameter of $12 \mu \mathrm{m}$ made of basalt roving without a lubricator showed that over time it loses all strength characteristics and sometimes completely destroyed, as the fibers, after the reaction with the aggressive environment of concrete are reduced in diameter to $4 \mu \mathrm{m}$. When using fibers made from basalt roving with the lubricant, the adhesion with cement mass is virtually nonexistent.

Low adhesions with the cement binding agent also have polyamide and polypropylene fiber (see Fig. 3).

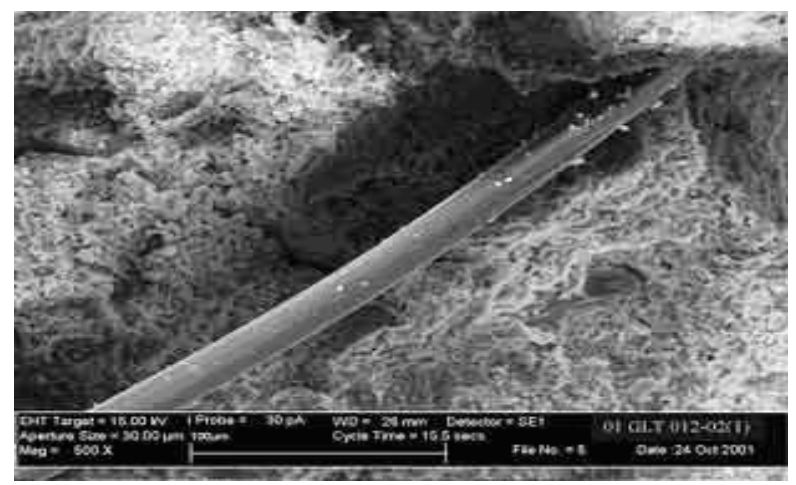

Fig. 3. The adhesion of the cement binder and polyamide fibers. 
Studies were carried out to determine the loss of strength of fiber produced from continuous basalt fiber without lubricant when it was in the liquid phase of solidifying Portland cement concrete under normal conditions. The results of the experiments are given in Table 1.

Table 1. Strength of basalt fiber after being in the liquid phase of Portland cement concrete.

\begin{tabular}{|c|c|c|c|c|c|c|}
\hline \multirow{2}{*}{$\begin{array}{c}\text { Processing } \\
\text { time, hours }\end{array}$} & \multicolumn{6}{|c|}{ Diameter of basalt fiber, $\mu \mathrm{m}$} \\
\cline { 2 - 7 } & \multicolumn{7}{|c|}{12} & \multicolumn{2}{c|}{20} & \multicolumn{2}{c|}{40} \\
\cline { 2 - 7 } & $\mathrm{GPa}$ & $\%$ & $\mathrm{GPa}$ & $\%$ & $\mathrm{GPa}$ & $\%$ \\
\hline 0 & 1.05 & 100 & 0.72 & 100 & 0.55 & 100 \\
\hline 3 & 0.84 & 80.0 & 0.70 & 97.2 & 0.55 & 100 \\
\hline 24 & 0.8 & 76.2 & 0.68 & 94.4 & 0.54 & 98.2 \\
\hline
\end{tabular}

By results of the conducted researches it is possible to recommend basalt fiber for disperse reinforcement of concrete. Having a high temperature resistance (up to $800{ }^{\circ} \mathrm{C}$ ), the products are characterized by high bending strength, tensile and shear. In addition, they have reduced water absorption, increased frost resistance, crack resistance, impact strength, abrasion resistance, durability and the like. Application for reinforcement of concrete, basalt fiber, made of coarse basalt fiber, allows you to: increase the strength of the concrete to $30 \%$; reduce the delamination of the concrete mixture to $40 \%$; reduce the time of primary and final hardening by $25 \%$.

The main advantages of using basalt fiber for the reinforcement of concrete and foam blocks are that even a small addition of these fibers can increase the resistance of structures to bending loads. Reinforced foam blocks are highly resistant to shock loads, incombustibility and vibration resistance. Basalt fiber prolongs the life of the erected buildings, reduces their shrinkage deformation and reduces cracking. As a consequence, foam blocks reinforced with basalt fiber, allow to reduce the overall weight of building structures, labor costs for reinforcement works and reduce construction time (see Fig. 4). Reinforced roving or fiber construction can be built on weak grounds and effectively solve the problems of saving energy and raw materials. If we summarize all the advantages that basalt fiber provides and foam-reinforced foam blocks, they are included in the reduction of economic costs for the construction of facilities, ensuring their reliable and durable operation.

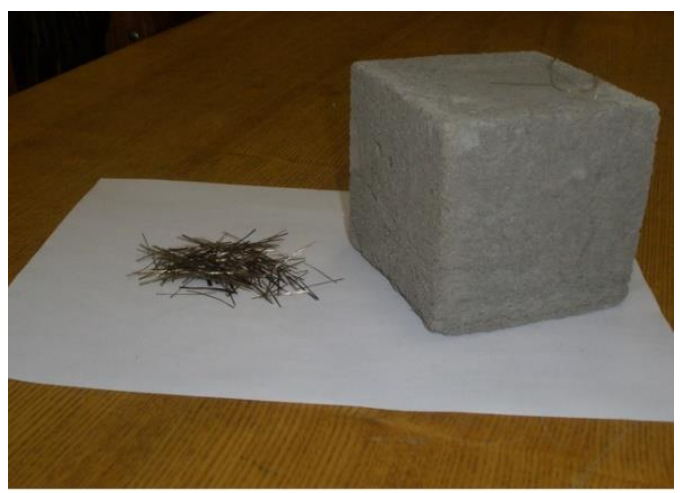

Fig. 4. Basalt fiber and foam fiber concrete block. 
The experience of using basalt fiber by various companies has shown that it can be introduced into foamed concrete in any of the following ways: fiber is poured into a concrete mixer (mixer) in a dry mix before adding water. For better distribution of the fibers, it is necessary to fill the fiber portion-wise in the aggregate during mixing; the fiber is added in small portions to the concrete while mixing directly into the mixer.

Using the first method, you can achieve a more uniform fibers distribution in concrete. Fiber consumption per $1 \mathrm{~m} 3$ of concrete $(6 \mathrm{~mm}$ long) is $0.5-1 \mathrm{~kg}$.

The study of the mixtures' properties with the use of expanded vermiculite (Table 2) showed that the compositions can be used, including exterior surface plastering, as well as in masonry mortars.

Table 1. Compositions and properties of plaster mixtures using expanded vermiculite.

\begin{tabular}{|c|c|c|c|c|c|c|c|}
\hline \multirow{3}{*}{ Item } & \multicolumn{3}{|c|}{$\begin{array}{l}\text { Consumption per } 1 \mathrm{~m} 3 \text { of } \\
\text { mixture }\end{array}$} & \multirow{3}{*}{$\begin{array}{l}\text { Average } \\
\text { density, } \\
\mathrm{kg} / \mathrm{m} 3\end{array}$} & \multirow{2}{*}{\multicolumn{2}{|c|}{ Strength, $\mathrm{MPa}$}} & \multirow{3}{*}{$\begin{array}{c}\text { Thermal } \\
\text { conductivity, } \\
\mathrm{W} /(\mathrm{m} \cdot \mathrm{K})\end{array}$} \\
\hline & \multirow{2}{*}{$\begin{array}{l}\text { Cement, } \\
\text { kg }\end{array}$} & \multirow{2}{*}{$\begin{array}{l}\text { Sand, } \\
\mathrm{kg}\end{array}$} & \multirow{2}{*}{$\begin{array}{l}\text { Vermiculite, } \\
\quad \mathrm{dm} 3\end{array}$} & & & & \\
\hline & & & & & Compression & Bend & \\
\hline 1 & 490 & 250 & 860 & 1080 & 4.5 & 2.4 & 0.25 \\
\hline 2 & 430 & 300 & 830 & 1150 & 3.6 & 3.0 & 0.28 \\
\hline 3 & 380 & 400 & 790 & 1320 & 4.7 & 3.2 & 0.35 \\
\hline
\end{tabular}

The compositions can be used for plastering walls of bricks, ceramic stones, various building blocks and natural stones. The frost resistance of the outer plaster coating is at least F35.

When finishing the walls and ceilings inside the rooms, weather and frost resistance of plaster coatings are not so important. The optimal compositions of composite mortars are mixtures in the ratio of $1 / 2 / 6-1 / 3 / 8$ by volume of Portland cement/lime/expanded vermiculite. Mixtures of this composition have high plasticity and workability, and mortars have a relatively low average density and porosity sufficient for air exchange. The plaster surface is well rubbed; it turns out smooth, without defects.

\section{Conclusions}

Thus, based on the results of the studies, basalt fiber can be recommended for disperse reinforcement of concrete. Possessing a high temperature resistance (up to $800 \mathrm{o} \mathrm{C}$ ), products from basalt concrete is characterized by increased strength for bending, stretching and shearing. In addition, they have lowered water absorption; frost resistance, crack resistance, impact strength, resistance to abrasion, durability, etc. are applied. The application, for reinforcing concretes, basalt fiber made from coarse basalt fiber, allows: increase the branded strength of concrete to $30 \%$; reduce the delamination of the concrete mix to $40 \%$; reduce the time of primary and final hardening by $25 \%$.

In addition to the main function, plaster mixtures using expanded perlite have: good sound-absorbing and sound-proofing properties; flame retardant properties; high vapor permeability of mortars creates an optimal mode for human life indoors. Plaster dry mixtures can perform decorative functions; they are easily rubbed; they are environmentally friendly materials, harmless to humans. Preparation of the mortars and their application and use are no different from standard methods.

\section{References}

1. R.J. Akhtyamov, Building material 4, 24-26 (2011) 
2. P.I. Meshkov, V. Mokin, Building material 5, 12-14 (2000)

3. A.D. Zhukov, A.V. Chugunkov, A.O. Khimich, Industrial and civil construction 3, 2123 (2013)

4. B.M. Rumyantsev, A.D. Zhukov, A.V. Chugunkov, D.I. Aristov, Scientific Review 13, 128-131 (2015)

5. B.M. Rumiantcev, A.D. Zhukov, D.B. Zelenshikov, A.S. Chkunin, K.K. Ivanov, Yu.V. Sazonova, MATEC Web of Conferences 86 (2016) DOI: http://dx.doi.org/10.1051/matecconf/ 20168604027

6. A.D. Zhukov, A.V. Chugunkov, Herald MSUCE 1-2, 273-278 (2011)

7. S.A. Tkach, V.I. Telichenko, Ecology of urbanized territories in Moscow 2, 39-44 (2011)

8. B.M. Rumiantcev, A.D. Zhukov, E.Yu. Bobrova, I.P. Romanova, D.B. Zelenshikov, T.V. Smirnova, MATEC Web of Conferences 86 (2016) DOI: http://dx.doi.org/10.1051/matecconf/ 20168604036

9. A.D. Zhukov, N.V. Naumova, P.M. Mustafaev, N.A. Mayorova, Industrial and civil construction 7, 48-51 (2014)

10. V.N. Sokov, A.E. Beglyarov, A.A. Solntsev, A.A. Zhuravleva, A.S. Zhurbin, Internet Journal of VolgGASU 2(33), 1 (2014)

11. A.D. Zhukov, A.M. Orlova, T.A. Naumova, T.P. Nikushkina, A.A. Mayorova, Scientific-about vision 7, 209-212 (2015)

12. A.D. Zhukov, E.Yu. Bobrova, D.B. Zelenshchikov, R.M. Mustafaev, A.O. Khimich, Advanced Materials, Structures and Mechanical Engineering 1025-1026, 1031-1034 (2014) 